\title{
Recommendations of the Group of Experts of the Polish Society of Gynecologists and Obstetricians regarding gynecological examination and treatment of a minor person (01.01.2020)
}

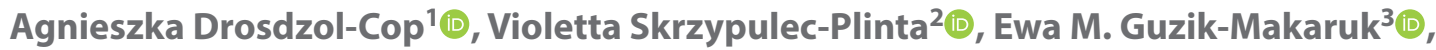 \\ Urszula Drozdowska ${ }^{4}$, Dorota Huzarska ${ }^{4}$, Iwona Joanna Czech ${ }^{1}$ (i) \\ ${ }^{1}$ Chair and Department of Gynecology, Obstetrics and Oncological Gynecology, Medical University of Silesia, Poland \\ ${ }^{2}$ Department of Woman's Health, School of Health Sciences in Katowice, Medical University of Silesia, Katowice, Poland \\ ${ }^{3}$ University of Bialystok, Poland \\ ${ }^{4}$ Legal Counsel, member of the Chamber of Legal Counsels in Bialystok, Poland
}

The recommendations present the current knowledge and procedures, which can be modified and changed in some cases, after careful analysis of a given clinical situation, which in the future may become the basis for their modification and updating.

According to the regulations of the Civil Code, a minor is a person under the age of 18. Exceptionally, a woman who turns 16 and gets married with the consent of the family court becomes an adult.

The gynecological examination is one of the most intimate procedures that can cause embarrassment in many women. Before visiting a gynecological clinic, a minor should be prepared for the examination by the mother, which will allow them to feel confident, reduce anxiety, and improve the minor's well-being before the examination.

Gynecological examination of a minor should be carried out by an experienced pediatric gynecologist. However, in emergency cases, injuries of the genital organs (i.e. emergent conditions), this examination can be performed by an experienced obstetrician-gynecologist or a doctor of other specialization who will provide proper care to the examination and medical documentation.

The indications for a gynecological examination of a minor are:

- abnormal vaginal bleeding;

- abdominal/lower abdominal pain; injuries of the genital organs, pelvis;

- suspected malformation of the genital organs;

- pubertal disorders;

- menstrual disorders;

- genital organ infections;

- suspected sexual abuse

- preventive examinations (not only in sexually active minors).

\section{MEDICAL HISTORY}

Taking medical history should be conducted with a minor patient and her representative present during the gynecological visit. According to the regulations of the Family and Guardianship Code, the legal representative is, in principle, the parent or legal guardian.

The interview should include:

- the minor's reason for visiting a gynecologist - symptoms;

- gynecological history: the course of the somatic and sexual development, the date of the first and last menstruation, characteristics of the menstrual cycle, sexual initiation, contraception, history of sexually transmitted infections;

- systemic diseases or other current diseases;

- illnesses and surgical procedures, treatment used;

- the course of pregnancy and childbirth, the neonatal period;

- family history of diseases: cardiovascular diseases, obesity, metabolic diseases, endocrinopathies, cancer;

- socioeconomic conditions of the family

\section{GENERAL PHYSICAL EXAMINATION}

The physical examination of a minor should be carried out in an atmosphere ensuring full privacy and intimacy, and with respect for the dignity of the examined person. At the outset, the purpose and nature of the study should be clarified. The general physical examination should evaluate: - general and emotional condition; 
- physical development (body weight, height, body mass index (BMI), body type, proportions, presence of dysmorphic features, malformations);

- the skin of the whole body (excluding the presence of symptoms related to physical violence);

- stage of sexual development (according to the Tanner scale);

- type of hair (female type, hypertrichosis, hirsutism - degree of intensity according to the Ferriman-Gallwey scale).

\section{GYNECOLOGICAL EXAMINATION}

Gynecological examination of a minor patient can be performed in the lithotomy position, "frog position" or knee-thoracic position on the gynecological chair or the mother's lap - in the most comfortable way for the minor patient. The examination should begin with a thorough assessment of the external genitalia (pubic hair, skin and mucosa of the external genitalia - labia majora and minor, clitoris, hymen, vaginal vestibule, external urethra, medial surfaces of thighs, buttocks, perineum, anus). Then, the presence and type of vaginal discharge should be assessed and, in selected clinical cases, material should be collected for bacteriological examination.

In young children and girls who are sexually inactive, a two-handed transrectal examination should be performed to assess the reproductive organ, and in some clinical cases (e.g. vaginal bleeding, the presence of a foreign body in the vagina, suspected malformations), child specula (heated, moistened $0.9 \% \mathrm{NaCl}$ solution) or a vaginoscope can be used. In sexually active girls, a gynecological examination should be performed through a vaginal speculum (appropriately selected vaginal speculum) and a two-handed examination. It is also recommended in this group of patients to collect a pap smear up to three years after sexual initiation.

In case of exceptional situations (urgent examination, genital or pelvic trauma, suspected presence of a foreign body in the vagina), a gynecological examination should be performed after administration of sedatives or under general anesthesia.

The last part of the gynecological examination is the ultrasound examination of the pelvic organs, which allows to assess: the degree of development and regularity of the genital organs, the thickness of the endometrium, the number and size of the ovarian follicles, and the detection of ovarian cysts and tumors. Ultrasound examination can be performed with a transabdominal probe with a full bladder or rectal probe (young children and girls sexually inactive) and a vaginal probe (sexually active girls).

For precise gynecological diagnostics in selected clinical situations, additional laboratory tests (e.g. hormonal tests, tumor markers) or imaging tests (computed tomography, magnetic resonance imaging) may also be recommended.

\section{MEDICAL INFORMATION}

After the gynecological examination, the minor should be informed about the result of the examination and the correct structure of her genital organs in a manner that is most understandable to her. A statutory representative and a minor over 16 years of age should be clearly informed about the health condition, diagnosis, proposed and possible diagnostic and treatment methods, treatment results and prognosis.

A pediatric gynecologist should also present to the statutory representative and a minor over 16 years of age the need for selected preventive examinations (including pap smear tests, with a recommendation every 12 months in sexually active minors) and the possibility of preventing HPV infections (protective vaccinations).

\section{LEGAL ASPECTS OF TREATMENT OF MINORS}

Legal issues related to the treatment of minors are regulated by: the Convention on the Rights of the Child adopted by the UN General Assembly on November 20, 1989; the Act of November 6, 2008 on the rights of the patient and the Patient's Rights Ombudsman, the Act of December 5, 1996 on the Professions of a Doctor and Dentist (Chapter 5. Principles of practicing the medical profession), Penal Code (Chapter XXV Offenses against sexual freedom and decency), the Code of Criminal Procedure (art. 304), the Family and Guardianship Code (title II, Section 1a, Chapter II, Relationships between parents and children).

The Code of Medical Ethics also plays an important role as a set of deontological principles addressed to the medical community.

A minor's visit to a gynecologist should take place in the presence of a statutory representative or actual guardian. According to Art. $3 \mathrm{sec} .1$ point 1 of the Act on Patient Rights and the Ombudsman for Patients' Rights, actual guardian means a person who, without statutory obligation, takes permanent care of a patient who requires such care due to age, health or mental state.

A minor may request a gynecological examination in intimate conditions - without the presence of a statutory representative/actual guardian, which should be recorded in the medical documentation. If the statutory representative/actual guardian does not consent to the examination without his presence, this fact should be noted in the medical documentation and the examination should be carried out in his presence.

In minors before the age of 16 , gynecological examination, diagnostic and treatment procedures (including pre- 
scribing contraceptives) require the consent of the statutory representative (an appropriate annotation should be made in the medical documentation). The fact of confirming the beginning of sexual intercourse should not be concealed from the legal representative of the minor. Additionally, about the fact of sexual intercourse, the doctor should notify the relevant authorities - the prosecutor's office, the police (pursuant to Art. 200 of the Penal Code and Art. $304 \$ 2$ of the Code of Criminal Procedure) in the case of minors under the age of 15 .

In minors before the age of 16 , gynecological examination, diagnostic and treatment procedures (including prescribing contraceptives) require the consent of the statutory representative (an appropriate annotation should be made in the medical documentation). The fact of confirming the beginning of sexual intercourse should not be concealed from the legal representative of the minor. Additionally, about the fact of sexual intercourse, the doctor should notify the relevant authorities - the prosecutor's office, the police (pursuant to Art. 200 of the Penal Code and Art. $304 \$ 2$ of the Code of Criminal Procedure) in the case of minors under the age of 15 .

It is possible to carry out a gynecological examination with the consent of the "actual guardian". However, undertaking other medical activities (than examination) requires the consent of the statutory representative each time. If it is not possible to reach an agreement with the legal representative, the appropriate permission is issued by the guardianship court. The guardianship court is also authorized to issue a substitute consent in the event of an objection by the statutory representative, when medical activities towards a minor under the age of 16 are - in the doctor's opinion - are necessary to eliminate the risk of loss of life or serious injury or serious health disorders.

In minors who are 16 years of age and under 18 years of age, a gynecological examination, diagnosis and treatment (including prescription of contraceptives) requires a parallel (double) consent - both the minor and his/her legal representative (please put an appropriate note in the medical records). Lack of consent of any of the above persons causes the illegality of the health service.
It is also possible to conduct examination on the basis of the parallel consent of a minor and his de facto (actual) guardian in the absence of a statutory representative.

If one of the persons authorized to give parallel consent (a minor over 16 years of age or their statutory representative/actual guardian) objects to the provision of a health service, including an examination, a consent of the guardianship court is required.

The consent to diagnostic and therapeutic procedures involving increased risk should be given in writing.

An emergency situation (requiring immediate medical assistance), when it is not possible to communicate with the legal representative/actual guardian of the minor, allows the doctor to conduct an examination or provide another health service with no increased risk. In this situation, the doctor, if possible, should consult another doctor and note this fact in the medical records.

An emergent situation which is connected with the risk of loss of life, serious injury or serious health impairment allows for high-risk medical activities to be carried out without appropriate consent, if obtaining the consent of the guardianship court is impossible in a short time. In such cases, the physician is obliged to consult another physician, possibly of the same specialty, and notify the statutory representative, actual guardian or the guardianship court about the performed activities.

\section{REFERENCES}

1. Emans SJ. Office Evaluation of the Child and Adolescent. In: Pediatric and Adolescent Gynecology. Ed. Emans SJ, Laufer MR, Golgstein DP. 5th Edition. Lippincott Williams and Wilkins, Philadelphia 2005: 1-50.

2. Janiszewska B. Patient's consent to provide a health service. Intra-system view, Warszawa 2013: 476-488.

3. Szczygieł K, Szekalski T. The position of a minor in the process of consenting to a therapeutic procedure. Przegląd Prawniczy UW. 2013(1-2).

4. Świderska M. Patient's consent to the medical procedure. , Toruń 2007: 43-50.

5. The North American Society for Pediatric and Adolescent Gynecology. http://www.naspag.org/.

6. Thibaud E. Gynecologic Clinical Examination of the Child and Adolescent. In: Sultan C, Karger AG. ed. Pediatric and Adolescent Gynecology. Evidence-Based Clinical Practice. , Switzerland 2004: 1-8.

7. MacDougall J. The needs of the adolescent patient and her parents in the clinic. In: Balen AH. ed. Pediatric and Adolescent Gynecology. A Multidisciplinary Approach. Ed. Balen AH. 1st Edition. Cambridge University Press, Cambridge 2004: 179-192. 